\title{
Effect of Nanosilica and Aluminum Hydroxide on Thermal, Flammability, and Morphology Properties of Nanocomposite made of Recycled High-Density Polyethylene and OCC Flour
}

\begin{abstract}
Ahmad Samariha *,a and Behzad Bazyar ${ }^{\mathrm{b}}$
Effects of nanosilica and aluminum hydroxide were considered relative to thermal, flammability, and morphological properties of nanocomposites from recycled high-density polyethylene (rHDPE) and old corrugated container (OCC) pulp. Amounts of 50\% recycled high-density polyethylene and $50 \%$ OCC flour were used. The nanosilica was used at three weight levels of $0 \%, 5 \%$, and $10 \%$. Lastly, aluminum hydroxide at a constant level of $5 \%$ and maleic anhydride grafted polyethylene at a constant level of $3 \%$ were mixed by twin screw extruders. The samples were made using a hand-press. The thermal and flammability properties were then measured. To consider the structure and function of nanosilica, the morphological characteristics of wood-plastic composites (WPC) were studied by X-ray diffractograms (XRD) and scanning electron microscopy (SEM) analyses. The results showed that increasing the nanosilica content up to $10 \%$ increased the thermal stability, and more charcoal was retained. Moreover, the limited oxygen index increased. X-ray diffractograms showed that the width and peak intensity decreased with the increased intake of silica nanoparticles. The SEM images showed that more adaptability was achieved through increasing the amount of nanosilica. Additionally, better and more homogenous bonds were observed between the fibers and connection matrix, and fewer gaps and pores were observed.
\end{abstract}

Keywords: Wood plastic composite (WPC); Recycled polyethylene; Nanosilica; Aluminum hydroxide; Thermal properties and morphological properties

Contact information: a: Young Researchers and Elites Club, Science and Research Branch, Islamic Azad University, Tehran, Iran; $b$ : Department of Wood and Paper Science and Technology, College of Agriculture and Natural Resources, Science and Research Branch, Islamic Azad University, Tehran, Iran;

* Corresponding author: a.samariha@gmail.com

\section{INTRODUCTION}

A wood-plastic composite (WPC) is a compound of polymer and cellulosic materials (Samariha et al. 2013). The WPC is an environmentally friendly material and needs less preservation when compared to wood. It has a similar appearance to wood with more efficiency. Some of the useful capabilities of WPC are less moisture absorbance, resistance against oxidation, resistance against infiltration and destruction by insects, low weight and high durability, high dimensional consistency, preferable physical and mechanical characteristics, long life, cutting, nailing and beveling capabilities, and use in decorative coatings.

Each day, a discernible sum of plastic waste enters into the environment. For the most part, polypropylene (PP), polyethylene terephthalate (PET), polystyrene (PS), 
polyvinyl chloride (PVC) and polyethylene (PE) are the most prominent parts of plastics in urban solid wastes (Beigloo et al. 2020). In particular, polyethylene (PE) is one of the foremost broadly utilized thermoplastics because of its combination of cheapness, high chemical resistance and good mechanical properties (Dorigato et al. 2019).

Using wooden and non-wooden fibers as boosters of thermoplastics are drastic enhancements and have been used during the last few years. Although there are various advantages to a WPC, its function against fire is a basic weak point of the material (Nemati et al. 2016).

Like most organic materials, polymers and wood are sensitive toward fire. Wood has a non-thermoplastic nature. Therefore, in contrast with polymers, its thermal decomposition temperature is less than its glass transfer and melting temperatures, so it can reach thermal decomposition without melting (Ahmad et al. 2015). The released heat of ignition of typical polymers, such as polyethylene and polypropylene, is approximately three times more than that of wood (Seefeldt and Braun 2012). Because of the presence of a polymer in the structure of a WPC, this product has more inflammability risk than wood. Therefore, improvement of WPC's behavior against fire to provide safety necessities is important (Bakar et al. 2010).

As a disadvantage, a high flame retardants loading is required to obviously increase the flame resistance of the resulting materials, with negative impacts on the processability and the ductility of the polymer (Zaghloul and Zaghloul 2017). To overcome this overwhelming restriction, it is conceivable to in part supplant metal hydroxides with another filler with flame retardants properties (i.e. nanoclay, zinc oxide and fullerene (C60) (Kiaei et al. 2017; Pan et al. 2017; Khakifirouz et al. 2019). In the event that the chosen fillers act synergistically, the same fire resistance can be accomplished with a lower flame retardants amount (Dorigato et al. 2019). Among the nanofillers utilized as fire retardants, nanosilica has been explored either alone or in combination with other flame retardants (Qian et al. 2016)

Flame retardant additives that have been used in making WPCs are silicon and zinc (Giancaspro et al. 2009).

Metal hydroxides are other flame retardant materials that are suitable for application in polyolefin (Georlette et al. 2000). These hydroxides are usually based on aluminum and magnesium and work more effectively when they are used as hydrate compounds. Decomposition of such compounds can lead to the production of water vapor that causes dilution of flammable gases. The required heat for dehydrating them can prevent fire development. In addition, metal hydroxides can reduce smoke by absorbing carbon materials (Giancaspro et al. 2009; Stark et al. 2010). Aluminum hydroxide has been used as a flame retardant material (Daimatsu et al. 2007).

A few researchers have endeavored to take advantage of synergies in the use of fire retardants to decrease the metal hydroxide content. Yen et al. (2013) examined the impact of aluminum hydroxide and nanoclay on the fire execution of ethylene-propylene-diene monomer (EPDM) rubber. The substitution of a portion of aluminum hydroxide with nanoclay was demonstrated successful to increase the resistance to the thermo-oxidative degradation and the limiting oxygen index (LOI), and in reducing the peak heat-release rate and the maximal smoke density.

Flame retardant materials can act physically or chemically regarding their natures. Chemical methods can occur through the interference of free radicles in the ignition procedure and prevent flame development in the inner sides. Physical actions can occur by reducing the environmental temperature through an endothermic reaction, preventing the 
fire from spreading by substituting oxygen with non-inflammable gases, and facilitating the formation of an impenetrable preserving surface layer (Moon and Farris 2009).

The aim of this study was to investigate the effect of nanosilica and aluminum hydroxide on the thermal, flammability, and morphology properties of the nanocomposite. The nanocomposite was made of recycled high-density polyethylene and OCC flour.

\section{EXPERIMENTAL}

\section{Materials}

The OCC pulp (Iran Cartoon Co., Tehran, Iran) was used as a powder filler in the polymer matrix. After preparation, they were meshed using a lab sieve. In this study, the OCC flour passed through a 50-mesh sieve and the remains on the sieve passed through a 60-mesh screen.

High-density polyethylene (HDPE) (HD5620, Shazand Arak Petrochemicals, Arak, Iran) with a melt flow index (MFI) of $20 \mathrm{~g}$ per $10 \mathrm{~min}$ and a density of $0.956 \mathrm{~g}$ per $\mathrm{cm}^{3}$ were used in this research. To simulate the effect of recycling, polymers underwent the effect of a three-stage thermodynamic destruction using two spiral extruders (Brabender, Duisburg, Germany). The MFI of recycled HDPE samples was measured based on the ASTM D1238-04 (2004) standard using a Gottfert/M1-4 device (Rheometer Manufacturers, Buchen, Germany).

To create compatibility between the OCC flour and recycled HDPE, maleic anhydride grafted polyethylene (MAPE, Krangin Co. Karaj, Iran) with a melt flow index

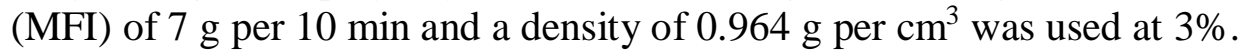

Nanosilica was made at Germany, Degussa Co. (Essen, Germany) and was used at three levels of 0,5 , and $10 \%$. The particle diameters were 11 to $13 \mathrm{~nm}$, their specific surface area was $200 \mathrm{~m}^{2}$ per $\mathrm{g}$, and their purity percentage was $99 \%$. The properties of the materials used and nanosilica are summarized in Table 1.

The aluminum hydroxide powder was made in Iran at Kimia Poyesh Bespar Co. (Esfahan, Iran) and was used at a constant level of 5\%.

Table 1. Specifications of the Nanosilica

\begin{tabular}{|c|c|}
\hline Property & Specification \\
\hline Silicon Oxide & $\mathrm{SiO}_{2}$ \\
\hline Purity & $99+\%$ \\
\hline Average Particle Size (APS) (nm) & 11 to 13 \\
\hline Specific Surface Area (SSA) & $200 \mathrm{~m}^{2} / \mathrm{g}$ \\
\hline Bulk Density & $<0.10 \mathrm{~g} / \mathrm{cm}^{3}$ \\
\hline Color & White \\
\hline Moisture & $<2 \%$ \\
\hline Weight Loss on Ignition & $30 \%$ \\
\hline Certificate of Analysis & Specification \\
\hline $\mathrm{SiO}$ & $<99 \%$ \\
\hline $\mathrm{Ti}$ & $<120 \mathrm{ppm}$ \\
\hline $\mathrm{Ca}$ & $<70 \mathrm{ppm}$ \\
\hline $\mathrm{Na}$ & $<50 \mathrm{ppm}$ \\
\hline $\mathrm{Fe}$ & $<20 \mathrm{ppm}$ \\
\hline${ }^{*}$ Note: According to the producer information & \\
\hline
\end{tabular}




\section{Methods}

Material mixture

The recycled high-density polyethylene (rHDPE), OCC flour, coupling agent (MAPE), nanosilica, and aluminum hydroxide were mixed together (Table 2).

Table 2. Weight Percentage of Components of Various Treatment Compounds in the Wood-plastic Composite

\begin{tabular}{|c|c|c|c|c|c|}
\hline $\begin{array}{c}\text { Treatment } \\
\text { Code }\end{array}$ & $\begin{array}{c}\text { OCC Flour } \\
(\%)\end{array}$ & $\begin{array}{c}\text { Recycled HDPE } \\
(\%)\end{array}$ & Nanosilica* $^{*}$ & ATH $^{*}$ & MAPE $^{*}$ \\
\hline A1 & 50 & 50 & 0 & 5 & 3 \\
\hline A2 & 50 & 50 & 5 & 5 & 3 \\
\hline A3 & 50 & 50 & 10 & 5 & 3 \\
\hline Recycled HDPE: Recycled High-density polyethylene; & & \\
MAPE: Maleic anhydride grafted polyethylene \\
ATH: Aluminum hydroxide; \\
*Based on total weight of wood-plastic composite
\end{tabular}

To mix the polymer matrix with the OCC flour, a reciprocating screw extruder (Model TSE20, Brabender Co., Duisburg, Germany) was used. After mixing, the external materials from the extruder were transformed to granules using a semi-industrial mill (WIESER, WG-LS 200/200, Hamburg, Germany).

\section{Sample preparation}

First, the obtained granules from each compound were oven dried for $24 \mathrm{~h}$ at $80^{\circ} \mathrm{C}$. This was done to make the limited oxygen index (LOI), thermogravimetric analysis (TGA), and X-ray diffractograms (XRD) samples using a mini test press (Toyoseiki Company, Tokyo, Japan). Samples were made at $200{ }^{\circ} \mathrm{C}$ for 4 min and were put under $25 \mathrm{MPa}$ of pressure. Next, the boards were cooled to $80{ }^{\circ} \mathrm{C}$ and during the cooling procedure the pressure continued. Before thermal tests, the samples were kept under climatic conditions (temperature $20 \pm 2{ }^{\circ} \mathrm{C}$ and moisture $65 \% \pm 5 \%$ ) for 2 weeks to reach a balanced moisture content.

\section{Thermogravimetric analysis (TGA)}

The Thermogravimetric analysis (TGA) measurement was performed using a thermal analyzer (TGA Q50; PL-150, Agilent Technologies, Santa Clara, CA, USA) for 7 $\mathrm{mg}$ of the test samples. The samples were evaluated at a temperature range of 25 to $600{ }^{\circ} \mathrm{C}$ and a heating rate of $15^{\circ} \mathrm{C}$ per min.

\section{$X$-ray diffractograms}

To measure the relative intercalation of nanosilica particles, an XRD device (X'Pert, Philips Co., Eindhoven, Netherlands) was used. The experiment was performed with a Co lamp at the wavelength of $1.79 \mathrm{Co}-\mathrm{K} \alpha$, a step of $0.02^{\circ}$, speed of $0.3^{\circ}$ per s, and at $2 \theta$ angles of $20^{\circ}$ to $80^{\circ}$. The samples were prepared as sheets with dimensions of $10 \times$ $10 \times 1.2 \mathrm{~mm}$ (length $\mathrm{x}$ width $\mathrm{x}$ thickness) and the electronic adjustments of the device were $30 \mathrm{~mA}$ and $40 \mathrm{KV}$.

\section{Limited oxygen index (LOI)}

The limited oxygen index (LOI) measurement were carried out using a FTA flammability unit, (Stanton Redcroft S/N710, Epsom, UK) according to the ASTM D- 
2863-13 (2013) standard. This method was used to determine the minimum concentration of oxygen in an oxygen/nitrogen mixture that will support a flaming burn in a testing specimen. The sample dimensions were of $15 \mathrm{~mm}$ length, $50 \mathrm{~mm}$ width, and $1.2 \mathrm{~mm}$ thickness. During the test, a certain volumetric concentration of the specimen in a tube was ignited with a hydrogen flame on top of the sample. The flame was achieved through gradually varying the oxygen and nitrogen gas concentration at fixed rates. For each treatment level, three replicates were measured for LOI and the average values and standard deviation were reported.

\section{Morphological analysis by SEM}

The morphology of composites was characterized using a scanning electron microscopy (SEM, Model AIS2100, Seron Technology, Gyeonggi-do, Korea) set at a 0.5 $\mathrm{kV}$ to $30 \mathrm{kV}$ accelerating voltage. Samples were to begin with frozen in fluid nitrogen and after that broken to guarantee that the microstructure remained clean and intaglio. The examples were coated with a gold layer to supply electrical conductivity.

\section{RESULTS AND DISCUSSION}

\section{Melt Flow Index}

The MFI was measured in specific thermal and sectional conditions. This property shows the rate of fluidity of the polymer. The MFI does not display the viscoelastic behavior of the polymer. The results showed that the MFI of HDPE increased after recycling three times from $20 \mathrm{~g}$ per $10 \mathrm{~min}$ for the pure polymer to $36.17 \mathrm{~g}$ per $10 \mathrm{~min}$. The increase of the frequency of recycling under the influence of thermodynamic factors causes reduction in the crystallinity and average molecular weight of polyethylene (increase of MFI). For HDPE, similar results were reported by other researchers (Abad et al. 2004).

\section{Thermogravimetric Analysis}

The effect of the nanosilica percentage on the weight loss percentage of WPC in the recycled polyethylene/OCC flour is displayed in Table 3 and Fig. 1. The results of the rate in the residual ash related to the thermal decomposition are given in Table 3 . With an increased rate of nanosilica, the rate of remaining ash increased.

Thermogravimetric analysis was used as a suitable instrument to determine the stability of the composite in different temperature conditions and to study the trend of the analysis results from heating. Table 3 shows the temperature of destruction in different percentages of weight loss and the remaining weight at the temperature of $600{ }^{\circ} \mathrm{C}$ for the wood-plastic nanocomposite. It was specified from the information in Table 3 that a 5\% weight loss occurred for the samples with no nanosilica at $296{ }^{\circ} \mathrm{C}$ and for the samples with $10 \%$ nanosilica at $295{ }^{\circ} \mathrm{C}$. When the thermal temperature reached $330{ }^{\circ} \mathrm{C}$ in the sample with $0 \%$ nanosilica, there was a $10 \%$ weight loss. In the sample that contained $10 \%$ nanosilica, this amount of weight loss occurred at $320{ }^{\circ} \mathrm{C}$. In the sample that contained $0 \%$ nanosilica, the weight loss occurred at $493{ }^{\circ} \mathrm{C}$ and the sample with $10 \%$ nanosilica occurred at $652{ }^{\circ} \mathrm{C}$. The results of the remaining ash (remaining weight) related to the thermal analysis are shown in Table 3 . With increasing nanosilica, the weight loss of the sample occurred at a higher temperature. Additionally, with the increased rate of nanosilica in different treatments, the rate of residual ash increased. The remaining ash content at 600 ${ }^{\circ} \mathrm{C}$ when used from 0,5 , and $10 \%$ nanosilica was $11.51,15.66$, and $20.6 \%$, respectively. 
Table 3. Temperatures at Various Percentages of Weight loss of Nano WPCsSamples Including Nanosilica and Recycled High-density Polyethylene

\begin{tabular}{|c|c|c|c|c|c|c|c|c|c|}
\hline & $\begin{array}{c}\text { Weight } \\
\text { Loss }\end{array}$ & $\mathbf{5 \%}$ & $\mathbf{1 0 \%}$ & $\mathbf{2 0 \%}$ & $\mathbf{4 0 \%}$ & $\mathbf{6 0 \%}$ & $\mathbf{8 0 \%}$ & $\begin{array}{c}\text { Weight } \\
\text { Remaining at } \\
\mathbf{6 0 0} \mathbf{C}(\%)\end{array}$ & $\begin{array}{c}\text { Limiting } \\
\text { Oxygen } \\
\text { Index (\%) }\end{array}$ \\
\hline \multirow{2}{*}{$\begin{array}{c}\text { Treatment } \\
\text { Code }\end{array}$} & $\mathrm{A} 1$ & 296 & 330 & 368 & 459 & 479 & 493 & 11.51 & $22(0.34)$ \\
\cline { 2 - 9 } & $\mathrm{A} 2$ & 297 & 324 & 354 & 465 & 485 & 502 & 15.66 & $22.99(0.81)$ \\
\cline { 2 - 9 } & $\mathrm{A} 3$ & 295 & 320 & 351 & 463 & 487 & 652 & 20.6 & $24.11(0.47)$ \\
\hline
\end{tabular}

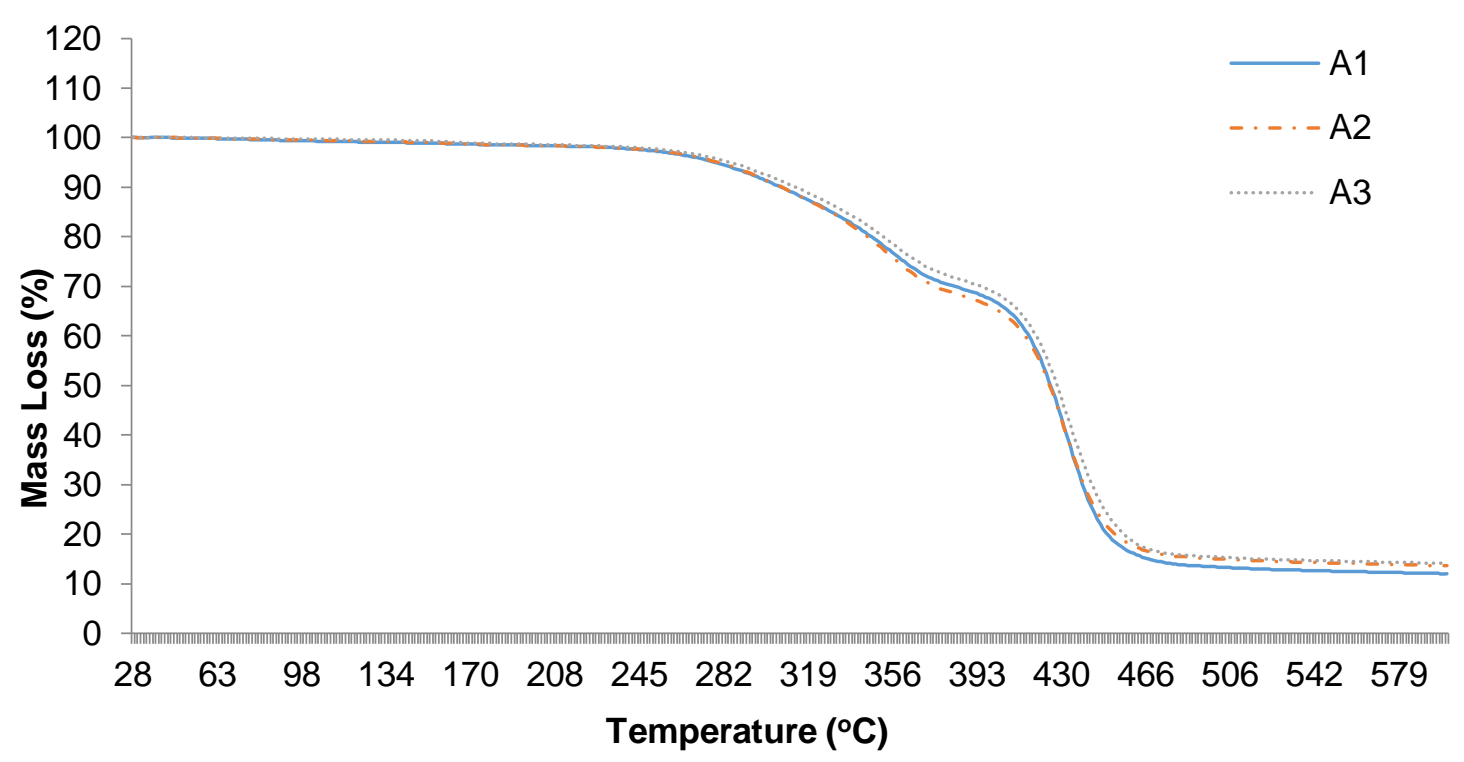

Fig. 1. TGA curves of the nanocomposites resulting from $50 \%$ OCC flour including 0,5 , and $10 \%$ nanosilica

The results showed that thermal stability increased with the enhancement of nanosilica. The more nanosilica enhancement led to nanocomposites beginning to degrade at higher temperatures. This means that samples lose weight at higher temperatures and resulted in more residual ash due to the mineral compounds of nanoparticles (Khosravian 2010). The most important factor in thermal stability caused by nanocomposites, is a semichar layer that is non-combustible. Eventually because of the high specific level of nanosilica and proper coating, thermal stability increases (Gilman et al. 2006). Moreover, the improvement of thermal stability can be attributed to the interaction between the polymer matrix of wood flour and nanosilica (Katsikis et al. 2007). This can be explained as a reduction in the movement of polymer chains via the effect of an increase of mineral materials. The reason for such an action is attributed to the proper interaction between the polymer and nanoparticles (Khosravian 2010). Deka and Maji (2012) observed that the thermal stability of polymer compounds increased through the addition of the coupling agent and wood floor. The level of initial degradation temperature was also increased after the addition of silica and clay nanoparticles.

The thermal stability of the polymer composition increases after the addition of the additive and wood flour. Additionally, the initial degradation temperature increased after adding silica and clay nanoparticles. 


\section{Flammability Behavior}

The estimation of LOI was completed using a limited oxygen index device. This index is a parameter for estimating the flammability and deterrence of polymers from fire. This number shows the minimum level of required oxygen for ignition with a stable flame in the mixture of oxygen and nitrogen gases.

Table 2 shows the effect of wood flour and nanosilica on the limited oxygen index. The WPC sample without nanosilica had a less limited oxygen index when compared with the sample with $10 \%$ nanosilica.

With the increase of nanosilica, the LOI increased. This meant that higher nanosilica levels led to a greater oxygen requirement for ignition. Therefore, increased nanosilica reduced the flammability of samples, and thus ignition was harder. The LOI was reduced by adding nanosilica due to the improvement in adhesiveness between the polymer and wood. Higher levels of LOI may have been the result of carbonaceous-silica char on the surface. A higher level of silica addition led to an increased char formation. Char produces black and tiny smokes that have a flame like a candle. Nanosilica can act like an obstacle that prevents penetration and movement of oxygen into a composites' structure. It can also act as an obstacle against gas penetration and fill the gaps (Nemati et al. 2016).

Composites mostly have pores and these pores were formed by vapor and volatile materials during mixture. Oxygen usually passes through these pores and increases the procedure of ignition, but the presence of nanoparticles interfered with the procedure by filling these pores. Additionally, it reduced the ignition level and increased the thermal stability (Kiaei et al. 2018). Erdem et al. (2009) observed an improvement in the flame postponement via the nanosilica addition.

It is believed that because of the obstacle effect of nanosilica, $\mathrm{O}_{2}$ penetration to the samples was reduced. Decomposition of the nanocomposite occurred at higher temperatures (Gilman et al. 2006). The results showed that the addition of nanosilica increased the thermal stability of composites. The most crucial factor in thermal stability, which was produced by nanoparticles, is the formation of a non-combustible char layer (Khosravian 2010). In addition, an enhancement of nanosilica particles could occupy part of the voids and reduce pores. Therefore, the accessibility of oxygen for ignition would be more difficult (Bazyar and Samariha 2017).

\section{SEM Analysis}

The distribution and compatibility between the fillers and matrix was observed in the SEM images. Figures 2 through 4 show fractured surfaces of the nanocomposite samples including $50 \%$ wood flour at the three levels of 0,5 , and $10 \%$ nanosilica.

Micrographs confirmed the results of the thermal tests in the composites. The effect of nanosilica on the interface of two phases of cellulosic and polymer fibers was considered by the SEM images. Gaps imply weak joint levels between the fiber and matrix and this showed that exposing stress and pressure can cause separation of weak joints from the matrix surface. The SEM pictures implied that more compatibility was produced via the addition of nanosilica. The images also showed the interface between the cellulosic material and polymer matrix increased and that better, stronger, and more monotonous joints were formed between the matrix and cellulosic fibers. These issues can be understood by considering the gaps' levels and uniformity of fracture surfaces on the composites. In addition, the increased LOI in these samples fairly confirmed the issue. The presence of nanosilica prevented movement of the volatile and flammable gases from pores and exiting from the inner side of composites toward their surface. Therefore, the presence 
of nanosilica increased the LOI (Bazyar and Samariha 2017). Nanosilica filled the gaps and acted as an obstacle against penetration and movement of oxygen toward nanocomposites' structure. It also acted as an obstacle against the penetration of gases.

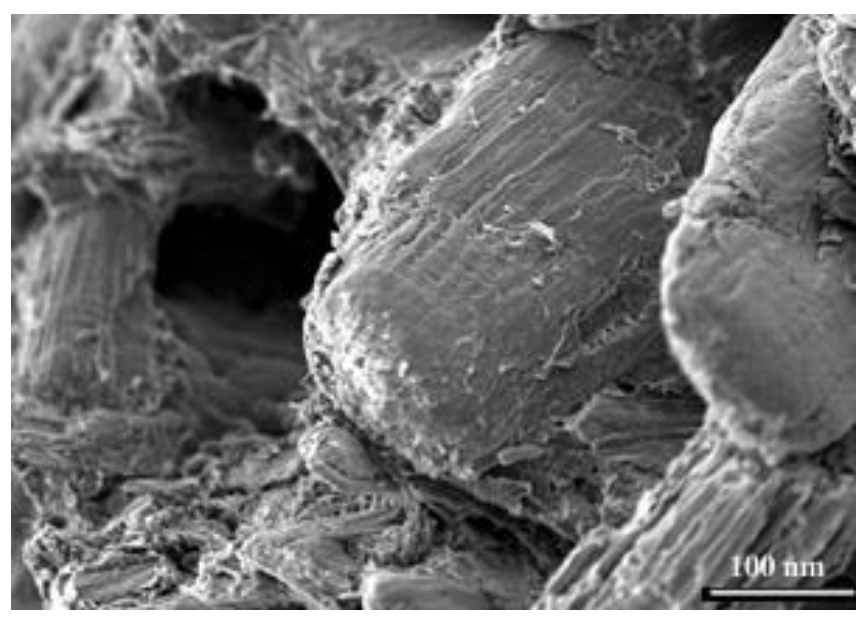

Fig. 2. SEM image of $50 \%$ OCC flour and $0 \%$ nanosilica

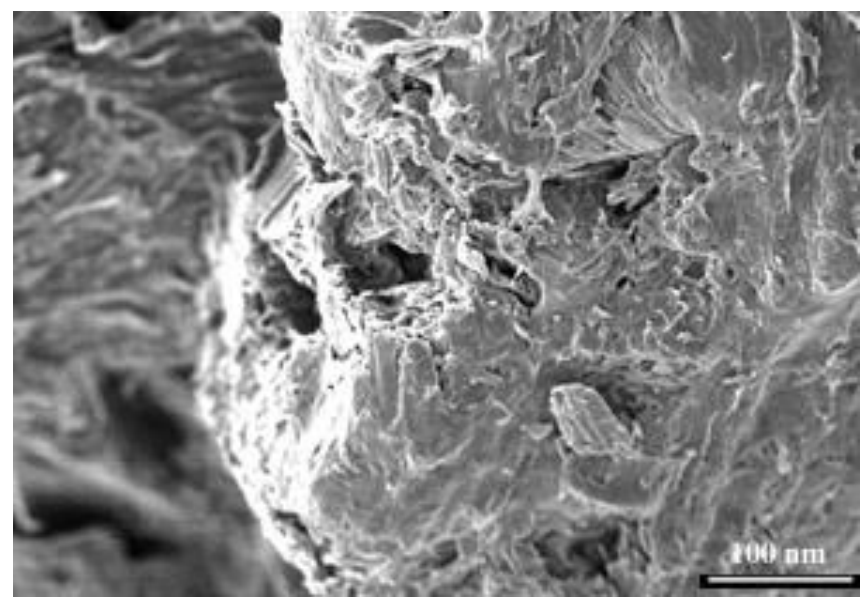

Fig. 3. SEM image of $50 \%$ OCC flour and $5 \%$ nanosilica

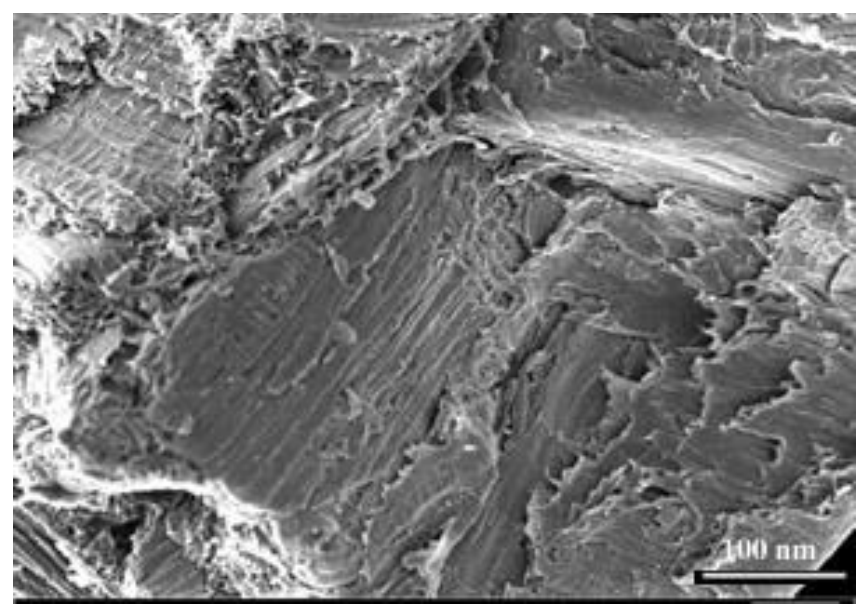

Fig. 4. SEM image of $50 \%$ OCC flour and 10\% nanosilica 


\section{X-Ray Diffractograms Analysis}

Figure 5 illustrates the patterns of diffractograms severity and angle $(2 \theta)$ for nanosilica powder and nanocomposites containing 0, 5, and 10\% nanosilica. Figure 5 shows that three peaks of diffractograms of pure nanosilica at $2 \theta$ equal $25.33^{\circ}$.

In nanocomposites that include various percentages of nanosilica, an increase of nanosilica from 0 to $10 \%$ reduced the crystalline severity. In addition, it was determined that severity degrees of other crystalline peaks were decreased. The reduction in the intensity of the crystalline peaks improved the amorphous section of the composite, which consisted of amorphous nanoparticles and wood flour. Figure 5 shows that the width and severity of the peak were decreased via enhancement of nanosilica, and this showed that the agglomeration phenomenon of silica particles occurred during use of higher levels of nanosilica. Deka and Maji (2012) considered the effect of nanosilica on polymer composites, and their results showed that enhancement of the silica level reduced the severity peak. This showed that nanosilica particles were injected into the WPC.

The crystalline top intensity of the polymer blend showed up within the range of $2 \theta$ $=21-24^{\circ}$ was found to decrease with the increment within the level of consolidation of nanosilica $(0,5$, and $10 \%)$. Comparable diminish in peak intensities of polymer and increment in peak intensity due to consolidation of $\mathrm{TiO}_{2}$ was watched and detailed by Mina et al. (2009), whereas considering the XRD profile of PP/titanium dioxide composite. This suggested that the nanosilica particles were scattered within the wood polymer matrix.

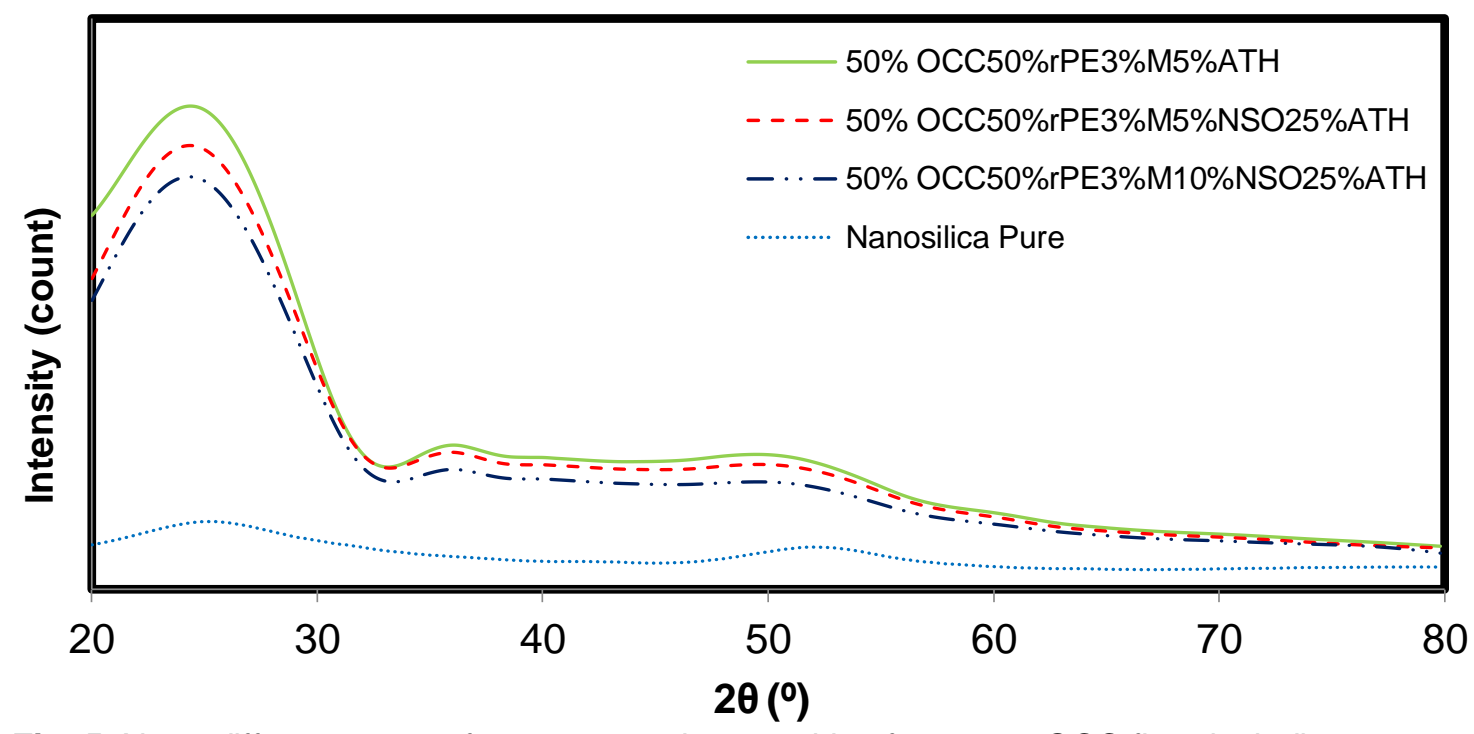

Fig. 5. X-ray diffractograms of nanocomposites resulting from 50\% OCC flour including 0,5 , and $10 \%$ nanosilica and pure nanosilica

\section{CONCLUSIONS}

This study investigated the effect of nanosilica and aluminum hydroxide on the thermal, flammability, and morphology properties of the nanocomposite made from OCC flour and recycled high-density polyethylene. The results were as follows:

1. An increased amount of nanosilica up to $10 \%$ increased the thermal stability. 
2. By increasing the nanosilica to $10 \%$, residual ash, and LOI increased.

3. The width and intensity of the X-ray diffractograms spectrum peak decreased when an increased amount of nanosilica was used.

4. The SEM pictures showed that an increase in nanosilica produced more compatibility and provided better, monotonous bonds between the fiber and polymer matrix. Fewer pores and gaps were also observed.

\section{ACKNOWLEDGEMENTS}

This research was funded by the Young Researchers and Elites Club, Science and Research Branch, Islamic Azad University, Tehran, Iran in the form of a research plan entitled "The effect of nano-silica and aluminum hydroxide on the thermal, flammability and morphology properties nanocomposite made from recycled polyethylene and OCC pulp" The authors appreciate the support received from the Young Researchers and Elites Club, Islamic Azad University of Science and Research Branch, Iran.

\section{REFERENCES CITED}

Abad, M., Ares, A., Barral, L., Cano, J., Diez, F., García-Garabal, S., Lopez, J., and Ramirez, C. (2004). "Effects of a mixture of stabilizers on the structure and mechanical properties of polyethylene during reprocessing," Journal of Applied Polymer Science 92(6), 3910-3916. DOI: 10.1002/app.20420

Ahmad, F., Choi, H. S., and Park, M. K. (2015). "A review: Natural fiber composites selection in view of mechanical, light weight, and economic properties," Macromolecular Materials and Engineering 300(1), 10-24. DOI: 10.1002/mame.201400089

ASTM D2863-13 (2013). "Standard test method for measuring the minimum oxygen concentration to support candle-like combustion of plastics," ASTM International, West Conshohocken, PA, USA.

Bakar, M. A., Ishak, Z. M., Taib, R. M., Rozman, H. D., and Jani, S. M. (2010). "Flammability and mechanical properties of wood flour-filled polypropylene composites," Journal of Applied Polymer Science 116(5), 2714-2722. DOI: 10.1002/app.31791

Bazyar, B., and Samariha, A. (2017). "Thermal, flammability, and morphological properties of nano-composite from fir wood flour and polypropylene," BioResources 12(3), 6665-6678. DOI: 10.15376/biores.12.3.6665-6678

Beigloo, J. G., Eslam, H. K., Hemmasi, A. H., Bazyar, B., and Ghasemi, I. (2020). "Nanographene's influence on a recycled high-density polyethylene/poplar wood flour nanocomposite," BioResources 15(1), 1233-1251. DOI:

10.15376/biores.15.1.1233-1251

Daimatsu, K., Sugimoto, H., Kato, Y., Nakanishi, E., Inomata, K., Amekawa, Y., and Takemura, K. (2007). "Preparation and physical properties of flame retardant acrylic resin containing nano-sized aluminum hydroxide," Polymer Degradation and Stability 92(8), 1433-1438. DOI: 10.1016/j.polymdegradstab.2007.05.012

Deka, B. K., and Maji, T. K. (2012). "Effect of silica nanopowder on the properties of wood flour/polymer composite," Polymer Engineering \& Science 52(7), 1516-1523. 
DOI: $10.1002 /$ pen.23097

Dorigato, A., Fredi, G., Fambri, L., Lopez-Cuesta, J. M., and Pegoretti, A. (2019). "Polyethylene-based single polymer laminates: Synergistic effects of nanosilica and metal hydroxides," Journal of Reinforced Plastics and Composites 38(2), 62-73. DOI: $10.1177 / 0731684418802974$

Erdem, N., Cireli, A. A., and Erdogan, U. H. (2009). "Flame retardancy behaviors and structural properties of polypropylene/nano- $\mathrm{SiO}_{2}$ composite textile filaments," Journal of Applied Polymer Science 111(4), 2085-2091. DOI: 10.1002/app.29052

Georlette, P., Simons, J., and Costa, L. (2000). "Halogen-containing fire-retardant compounds," in: Fire Retardancy of Polymeric Materials, A. F. Grand, and C. A. Wilkie, Marcel Dekker Inc., New York, NY, USA, pp. 245-284.

Giancaspro, J., Papakonstantinou, C., and Balaguru, P. (2009). "Mechanical behavior of fire-resistant biocomposite," Composites Part B: Engineering 40(3), 206-211. DOI: 10.1016/j.compositesb.2008.11.008

Gilman, J. W., Harris, R. H., Shields, J. R., Kashiwagi, T., and Morgan, A. B. (2006). “A study of flammability reduction mechanism of polystyrene-layered silicate nanocomposites: Layered silicate reinforced carbonaceous char," Polymers for Advanced Technologies 17(4), 263-271. DOI: 10.1002/pat.682

Katsikis, N., Zahradnik, F., Helmschrott, A., Münstedt, H., and Vital, A. (2007). "Thermal stability of poly (methyl methacrylate)/silica nano-and microcomposites as investigated by dynamic-mechanical experiments," Polymer Degradation and Stability 92(11), 1966-1976. DOI: 10.1016/j.polymdegradstab.2007.08.009

Khakifirouz, A., Samariha, A., Karbaschi, A., Benakachi, M. A., and Beigloo, J. G. (2019). "Nanoclay's influence on mechanical and thermal properties of a polypropylene/poplar wood flour nanocomposite," BioResources 14(4), 8267-8277. DOI: 10.15376/biores.14.4.8267-8277

Khosravian, B. (2010). Studying Mechanical, Physical, Thermal and Morphological Characteristics of Hybrid Composites of Polypropylene/Wood Flour/Wollastonite, Master's Thesis, University of Tehran, Tehran, Iran.

Kiaei, M., Kord, B., Samariha, A., Moghdam, Y. R., and Farsi, M. (2017). "Mechanical, flammability, and morphological properties of nano-composite plastic based on hardwood flour high-density polyethylene embedding by nano-zinc oxide," BioResources 12(3), 6518-6528. DOI: 10.15376/biores.12.3.6518-6528

Kiaei, M., Amiri, H., Samariha, A., and Amani, N. (2018). "Effect of nanosilica on thermal, flammability, and morphological properties of WF/RPS-based nanocomposites," Cerne 24(1), 59-66. DOI: 10.1590/01047760201824012383

Mina, M. F., Seema, S., Matin, R., Rahaman, M. J., Sarker, R. B., Gafur, M. A., and Bhuiyan, M. A. H. (2009). "Improved performance of isotactic polypropylene/ titanium dioxide composites: Effect of processing conditions and filler content," Polymer Degradation and Stability 94(2), 183-188. DOI: https://doi.org/10.1016/j.polymdegradstab.2008.11.006

Moon, S., Jo, B., and Farris, R. J. (2009). "Flame resistance and foaming properties of NBR compounds with halogen-free flame retardants," Polymer Composites 30(12), 1732-1742. DOI: 10.1002/pc.20794

Nemati, M., Eslam, H. K., Talaeipour, M., Bazyar, B., and Samariha, A. (2016). "Effect of nanoclay on flammability behavior and morphology of nanocomposites from wood flour and polystyrene materials," BioResources 11(1), 748-758. DOI: 10.15376/biores.11.1.748-758 
Pan, Y., Han, L., Guo, Z., and Fang, Z. (2017). "Improving the flame-retardant efficiency of aluminum hydroxide with fullerene for high-density polyethylene," Journal of Applied Polymer Science, 134(9), 134-142. DOI: https://doi.org/10.1002/app.44551

Qian, Y., Zhu, X., Li, S., and Chen, X. (2016). "Flame-retardant properties of ethylenevinyl acetate/oil sludge/fumed silica composites," RSC advances 6(67), 63091-63098. DOI: $10.1039 /$ C6RA03280J

Samariha, A., Bastani, A., Nemati, M., Kiaei, M., Nosrati, H., and Farsi, M. (2013). "Investigation of the mechanical properties of bagasse flour/polypropylene composites," Mechanics of Composite Materials 49(4), 447-454. DOI: 10.1007/s11029-013-9361-3

Seefeldt, H., and Braun, U. (2012). "A new flame retardant for wood materials tested in wood-plastic composites," Macromolecular Materials and Engineering 297(8), 814820. DOI: $10.1002 /$ mame.201100382

Stark, N. M., White, R. H., Mueller, S. A., and Osswald, T. A. (2010). "Evaluation of various fire retardants for use in wood flour-polyethylene composites," Polymer Degradation and Stability 95(9), 1903-1910. DOI: 10.1016/j.polymdegradstab.2010.04.014

Zaghloul, M. M. Y., and Zaghloul, M. M. Y. (2017). "Influence of flame retardant magnesium hydroxide on the mechanical properties of high density polyethylene composites," Journal of Reinforced Plastics and Composites 36(24), 1802-1816. DOI: $10.1177 / 0731684417727143$

Yen, Y. Y., Wang, H. T., and Guo, W. J. (2013). "Synergistic effect of aluminum hydroxide and nanoclay on flame retardancy and mechanical properties of EPDM composites," Journal of Applied Polymer Science 130(3), 2042-2048. DOI: 10.1002/app.39394

Article submitted: December 4, 2019; Peer review completed: February 2, 2020;

Revisions accepted: March 21, 2020; Published: March 25, 2020.

DOI: 10.15376/biores.15.2.3382-3393 